sensation in the head and was seized with a convulsion, and became unconscious. I reached her at 10:45 p. m., while she was in the second convulsion. This was severe, prolonged, and epileptiform in character. The tongue was bitten and much mucus collected in the throat. After the convulsion the face was flushed, the pupils were moderately dilated, and reacted to light. The respirations were shallow, slightly irregular, and more rapid than normal. The pulse was full, regular and 110 to the minute. She was completely unconscious.

Treatment and Result.-Apomorphin, 1/8 gr., and morphin sulphate, $1 / 4$ gr., were given hypodermically. Another severe convulsion soon occurred, followed by free emesis, the vomitus smelling strongly of tansy. No more convulsions occurred. As soon as swallowing was possible strong coffee was given, and at 1 a. $m$. consciousness began to return. Recovery was uneventful, save for great weakness, which, notwithstanding stimulative treatment, persisted for two or three days.

The desired emenagogue effect did not occur.

\section{A CASE OF INFANTILE SCURVY.}

\section{FRANK VAN DER BOGERT, M.D. SCHENECTADY, N. Y.}

I feel that I should apologize for presenting the report of a single case of a disease which can hardly be considered one of extreme rarity; yet this case has been of especial interest to me in view of its late diagnosis, coexisting conditions and etiology.

The patient was a boy of 19 months.

Family History.-The parents were well advanced in years at the time of his birth, the father being 54 and the mother nearly 4.1. The mother had borne two other children, one a boy now living and apparently well at 17 years of age, the other a girl, who died at the age of 2 months. There was an interval of about 13 years between the births of the above mentioned children and that of the patient under consideration.

Personal History.-He was apparently healthy at birth. He was nursed for two or three weeks, when the nursing had to be discontinued on account of the failure of the supply of milk. He was then put on a cream and water mixture, the proportions of which I am unable to give, for about two months. After this he was given Mellin's food, prepared according to the directions on the package for infants of his age. $\mathrm{He}$ remained perfectly well up to the holidays of 1905 , when he was about 13 months old. At this time he was circumcised by the physician who attended the mother in confinement. So far as I can learn the circumcision was done simply to relieve the local condition and for cleanliness. Very shortly thereafter the child began to fail, and apparently lost the use of his limbs. He became fearful of everyone, and there was decided general tenderness of the body surface. He continued to fail and inasmuch as the prepuce had become adherent in healing after the operation, a second operation (circumcision) was performed with a view to relieving the reflex nervous symptoms due to the local irritation.

Examination.-The fear and other nervous symptoms seemed steadily to increase, and the patient $w^{*}$ referred to me on April 1, 1905. At this time the child was so afraid of me, screaming with fright when I entered ti - room, that it was almost impossible to make an examination. The skin was extremely tender, and seemed especially so about the genitals, due probably to the fact that these parts were the seat of operation. There was paralysis of the lower extremities with decided muscular atrophy. The appetite was poor and the bowels were constipated. The gums, especially in the neighborhood of the central incisors, were inflamed, swollen and ecchymotic, and bled freely at times. The mouth was tender, and this interfered with the taking of food. (This condition of the gums was present, I learn, even as early as one month before the first operation, in November, 1905).

Treatment.-After deciding on the diagnosis of infantile scurvy, I took the child off the Mellin's food, to the prolonged use of which I attributed in great part the condition, and put him on a cream and water mixture with sugar of milk, on which he steadily improved. It was difficult, however, to in- duce him to take the mixture in sufficient quantity, and the improvement was not rapid enough to please the family, who had great confidence in the Mellin's food. At their request I put him back on the food for one day, but immediately changed to a diet of plain cow's milk, with beef juice and orange juice. From that time on the child gained steadily. His weight increased. The condition of the gums improved, and the paralysis of the extremities was relieved, the limbs becoming normal in appearance, and the muscles less flabby.

The most interesting point in the case to me was the attributing of the origin of the nervous symptoms to reflex irritation of the foreskin.

\section{'IHE USE OF A SMALL MIRROR IN STUDYING THE APEX BEAT. \\ ROBERT L. PITFIELD, M.D. PHILADELPHIA.}

Small mirrors have been affixed to galvanometers and the delicately moving parts of other instruments, and by means of beams of light thrown on the mirrors very fine movements may be detected and analyzed. A plate filled with mercury on which a beam of light is thrown, has been employed to detect the movements of the earth during earthquakes. By means of a small mirror pressed over the apex beat I have been able to demonstrate the movements of the apex of the heart in a case of StokesAdams disease. The movements were greatly amplified and it was easily possible with the beam of light to note the two kinds of impulses at the apex. In Stokes-Adams disease it has been found that the auricles and ventricles do not beat synchronously. A condition of heart block is brought about through disease of the bundle of His which conveys the contracting impulse, originating in the auricle, to the ventricle, and instead of a cardiac cycle consisting of an auricular beat and then a ventricular beat, we find that there are frequently from two to four more auricular beats than ventricular ones. The ratio often being one to two and a half or one to three and a half, so that we have an auricular pulse as an instance, of 72 to a ventricular one of 20 .

Phenomena of this sort may be demonstrated by taking pulse tracings of the apex beat or of the carotid and jugular pulse combined. Such tracings in this disease show a number of minor curves followed by a full high curve, three or four times as large as the minor curves, then several more minor ones and then a large one again. The minor curves in the cardiogram are produced by the auricular contractions, the full large curves are caused by the ventricular contractions.

In order to demonstrate the phenomena in StokesAdams disease, I placed the patient in a dorsal position on a table near a window, and after exposing his chest to bright sunlight, I pressed a one-inch laryngeal mirror over the apex. I found each cardiac movement caused the beam of light reflected from the mirror to the wall, four feet away, to move. The ventricular beat caused the spot of light to move from four to six inches, while the minor auricular contraction caused the spot of light to move only from one and a half to two inches.

The varying length of the excursion of the light beam was most marked. By fastening bits of mirror to the bulbous jugularis under similar conditions the auricular beat is shown in this way. Any apex phenomena, irregular or galloping rhythm may be studied in the same way. This method would not have any very great use in physical diagnosis, but it seems an excellent way to demonstrate the phenomena to students. 